\title{
Rice Crop Quality Evaluation Method through Regressive Analysis between Nitrogen Content and Near Infrared Reflectance of Rice Leaves Measured from Near Field
}

\author{
Kohei Arai ${ }^{1}$ \\ Graduate School of Science and Engineering \\ Saga University \\ Saga City, Japan
}

\begin{abstract}
Rice crop quality evaluation method through regressive analysis between nitrogen content in the rice leaves and near infrared reflectance measurement data from near field, from radio wave controlled helicopter is proposed. Rice quality dependency on nitrogen of chemical fertilizer and water supply condition is evaluated. Also homogeneity of the rice crop quality in the paddy fields is evaluated. Furthermore, influence due to shadow on near infrared reflectance of rice leaves measured from near field is taken into account in the rice crop quality evaluation processes.
\end{abstract}

Keywords-rice crop; regressive analysis; nitrogen content; reflectance measurement;

\section{INTRODUCTION}

Vitality monitoring of vegetation is attempted with photographic cameras [1]. Grow rate monitoring is also attempted with spectral reflectance measurements [2]. BiDirectional Reflectance Distribution Function: BRDF is related to the grow rate for tealeaves [3]. Using such relation, sensor network system with visible and near infrared cameras is proposed [4]. It is applicable to estimate nitrogen content and fiber content in the tealeaves in concern [5]. Therefore, damage grade can be estimated with the proposed system for rice paddy fields [6]. This method is validated with Monte Carlo simulation [7]. Also Fractal model is applied to representation of shapes of tealeaves [8]. Thus the tealeaves can be asse 3 ssed with parameters of the fractal model. Vitality of tea trees are assessed with visible and near infrared camera data [9].

One of the methods for monitoring the fields is to use remote sensing technology utilizing aircrafts, helicopters, hot air balloons, etc. with a wide field of view for monitoring relatively large scaled agricultural fields. In particular, there are remote sensing sensors which onboard radio controlled helicopters. Attitude stability of the radio controlled helicopters is getting well now a day. Field of view of the remote sensing sensors is good enough for relatively wide scale of agricultural fields.

One of the indexes which allows indicate quality of agricultural crops is nitrogen content in the agricultural crop leaves. The nitrogen content is proportional to the reflectance at
Near Infrared: NIR wavelength regions. Therefore, it is possible to estimate quality of agricultural crops with radio controlled helicopter based near infrared camera data.

Through experiments at the Saga Prefectural Agricultural Research Institute: SPARI for the period of rice crop growing, it is found that the proposed system works well for monitoring quality of the rice crops. Also it is found that the proposed method for nitrogen content estimation with near infrared camera data. Furthermore, it is capable to check rice crop quality distribution in the rice crop fields in concern. Then quality control which depends on location by location of the rice crop fields can be made with the quality monitoring results.

The following section describes the proposed monitoring system and nitrogen content estimation method based on the relation between nitrogen content in the rice crops and near infrared camera data followed by some experiments. Then conclusion is described together with some discussions.

\section{PROPOSED METHOD}

A. Regressive Analysis

Linear regressive equation is expressed in equation (1).

$N=a R+b$

where $N, R$ denotes measured Nitrogen content in leaves, and measured Near Infrared: NIR reflectance, respectively while $a$ and $b$ denotes regressive coefficients. There is well known relation between nitrogen content and NIR reflectance. Therefore, regressive analysis based on equation (1) is appropriate.

\section{B. Radio Controlled Helicopter Based Near Infrared \\ Cameras Utilizing Agricultural Field Monitoring System}

The helicopter used for the proposed system is "GrassHOPPER" 1 manufactured by Information \& Science Techno-Systems Co. Ltd. The major specification of the radio controlled helicopter used is shown in Table 1. Also, outlook of the helicopter is shown in Figure 1. Canon Powershot S100²

\footnotetext{
${ }^{1}$ http://www.ists.co.jp/?page_id=892

${ }^{2}$ http://cweb.canon.jp/camera/dcam/lineup/powershot/s110/index.html
} 
(focal length $=24 \mathrm{~mm}$ ) is mounted on the GrassHOPPER. It allows acquire images with the following Instantaneous Field of View: IFOV at the certain altitudes, $1.1 \mathrm{~cm}$ (Altitude $=30 \mathrm{~m}$ )

$3.3 \mathrm{~cm}$ (Altitude $=100 \mathrm{~m}$ ) and $5.5 \mathrm{~cm}$ (Altitude $=150 \mathrm{~m}$ ) .

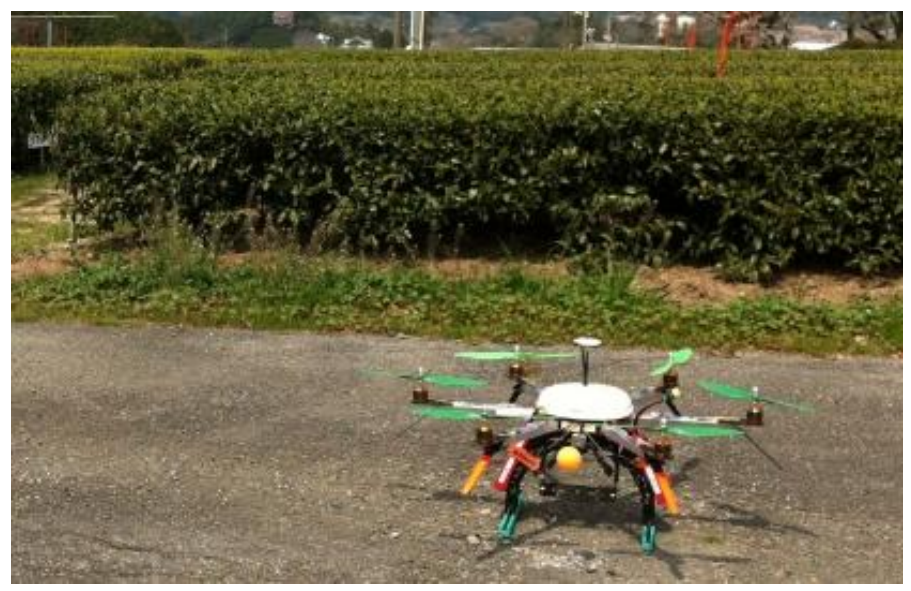

Fig. 1. Outlook of the GrassHOPPER

TABLE I. MAJOR SPECIFICATION OF GRASSHOPPER

\begin{tabular}{|l|l|}
\hline Weight & $2 \mathrm{~kg} \quad$ (Helicopter only) \\
\hline Size & $80 \mathrm{~cm} \times 80 \mathrm{~cm} \times 30 \mathrm{~m}$ \\
\hline Payload & $600 \mathrm{~g}$ \\
\hline
\end{tabular}

In order to measure NIR reflectance, standard plaque whose reflectance is known is required. Spectralon ${ }^{3}$ provided by Labsphere Co. Ltd. is well known as well qualified standard plaque. It is not so cheap that photo print papers are used for the proposed system. Therefore, comparative study is needed between Spectralon and the photo print papers.

The proposed system consist Helicopter, NIR camera, photo print paper. Namely, photo print paper is put on the agricultural plantations, tea trees in this case. Then farm areas are observed with helicopter mounted NIR camera. Nitrogen content in agricultural plants, rice crops in this case, is estimated with NIR reflectance.

\section{Proposed Method for Rice Crop Quality Evaluation}

Rice crop quality can be represented nitrogen content which is closely related to nitrogen content. Furthermore, it is well known that nitrogen content can be represented with NIR reflectance. Therefore, rice crops quality can be evaluated with measured NIR reflectance based on the equation (1).

The proposed method and tea farm area monitoring system with helicopter mounted NIR camera is based on the aforementioned scientific background.

\footnotetext{
${ }^{3}$ https://www.google.co.jp/search?q=spectral+labsphere\&hl=ja
}

\section{Rice Crop Field at Saga Prefectura; Agricultural Research Institute: SPARI}

Specie of the rice crop is Hiyokumochi ${ }^{4}$ which is one of the late growing types of rice species. Hiyokumochi is one of low amylase (and amylopectin rich) of rice species (Rice No.216).

Figure 2 and 3 shows layout of the test site of rice crop field at SPARI ${ }^{5}$ which is situated at $33^{\circ} 13^{\prime} 11.5^{\prime \prime}$ North, $130^{\circ} 18^{\prime} 39.6^{\prime \prime E a s t}$, and the elevation of $52 \mathrm{feet}$.

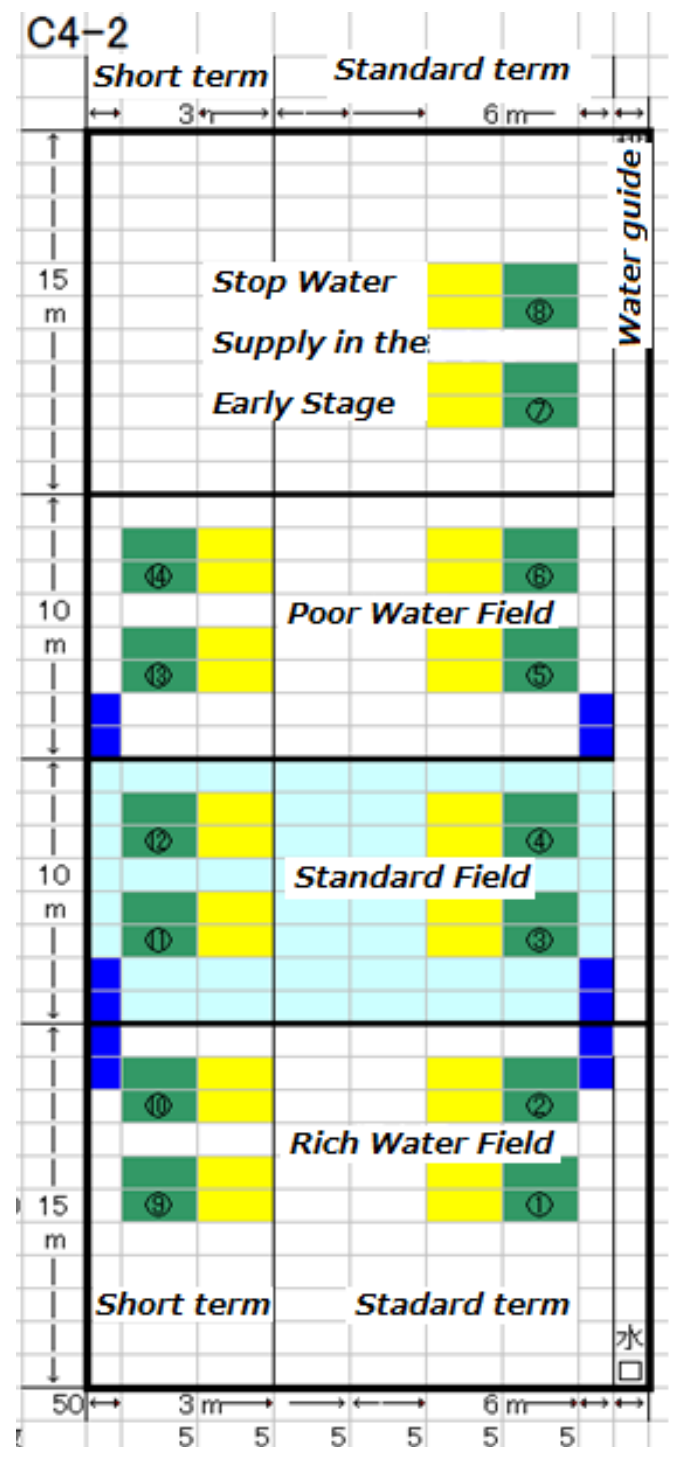

Fig. 2. Paddy field layout for investigation of water supply condition dependency on rice crop quality

The paddy field C4-2 is for the investigation of water supply condition on rice crop quality. There are 14 of the paddy field subsections of which water supply conditions are different each other.

There are two types of water supply scheduling, short term and standard term. Water supply is stopped in the early stage of

\footnotetext{
${ }^{4}$ http://ja.wikipedia.org/wiki/\%E3\%82\%82\%E3\%81\%A1\%E7\%B1\%B3

${ }^{5}$ http://www.pref.saga.lg.jp/web/shigoto/_1075/_32933/ns-

nousisetu/nouse/n_seika_h23.html
} 
rice crop growing period for the short term water supply subsection fields while water supply is continued comparatively longer time period comparing to the short term water supply subsection fields. Meanwhile, there are three types of water supply conditions, rich, standard, and poor water supply subsection fields.

On the other hand, test sites C4-3 and C4-4 are for investigation of nitrogen of chemical fertilizer dependency on rice crop quality. There are two types of paddy subsections, densely and sparsely planted paddy fields. Hiyokumochi rice leaves are planted 15 to 20 fluxes per $\mathrm{m}^{2}$ on June 22 2012. Rice crop fields are divided into 10 different small fields depending on the amount of nutrition including nitrogen ranges from zero to $19 \mathrm{~kg} / 10 \mathrm{a} /$ nitrogen.

Nitrogen of chemical fertilizer is used to put into paddy fields for five times during from June to August. Although rice crops in the 10 different small fields are same species, the way for giving chemical fertilizer are different. Namely, the small field No.1 is defined as there is no chemical fertilizer at all for the field while 9, 11, and $13 \mathrm{~kg} / 10 \mathrm{a} /$ nitrogen of after chemical fertilizer are given for No.2 to 4, respectively, no initial chemical fertilizer though. Meanwhile, 9, 11, $13 \mathrm{~kg} / 10$ $\mathrm{a} /$ nitrogen are given as after chemical fertilizer for the small field No.5, 6, and 7, respectively in addition to the $3 \mathrm{~kg} / 10$ a/nitrogen of initial chemical fertilizer. On the other hand, 12, 14 , and $16 \mathrm{~kg} / 10 \mathrm{a} /$ nitrogen are given for the small fields No.5, 6,7 , respectively as after chemical fertilizer in addition to the initial chemical fertilizer of $3 \mathrm{~kg} / 10 \mathrm{a} /$ nitrogen for the small field No. 15, 17, 19, respectively. Therefore, rice crop grow rate differs each other paddy fields depending on the amount of nitrogen of chemical fertilizer.

\section{EXPERIMENTS}

\section{A. Acquired Near Infrared Camera Imagery Data}

Radio wave controlled helicopter mounted near infrared camera imagery data is acquired at C4-2, C4-3, C4-4 in SPARI on 24 September 2012 with the different viewing angle from the different altitudes. Figure 4 shows an example of the acquired near infrared image. There is spectralon of standard plaque as a reference of the measured reflectance in between C4-3 and C4-4. Just before the data acquisition, some of rice crops and leaves are removed from the subsection of paddy fields for inspection of nitrogen content. Using the removed rice leaves, nitrogen content in the rice leaves is measured based on the Dumas method ${ }^{6}$ (a kind of chemistry method) with Sumigraph $\mathrm{NC}-220 \mathrm{~F}^{7}$ of instrument. The measured total nitrogen content is compared to the NIR reflectance.

The acquired near infrared camera imagery data is rectified and registered with geographic map of paddy field subsections as shown in Figure 5 (a) and (b).

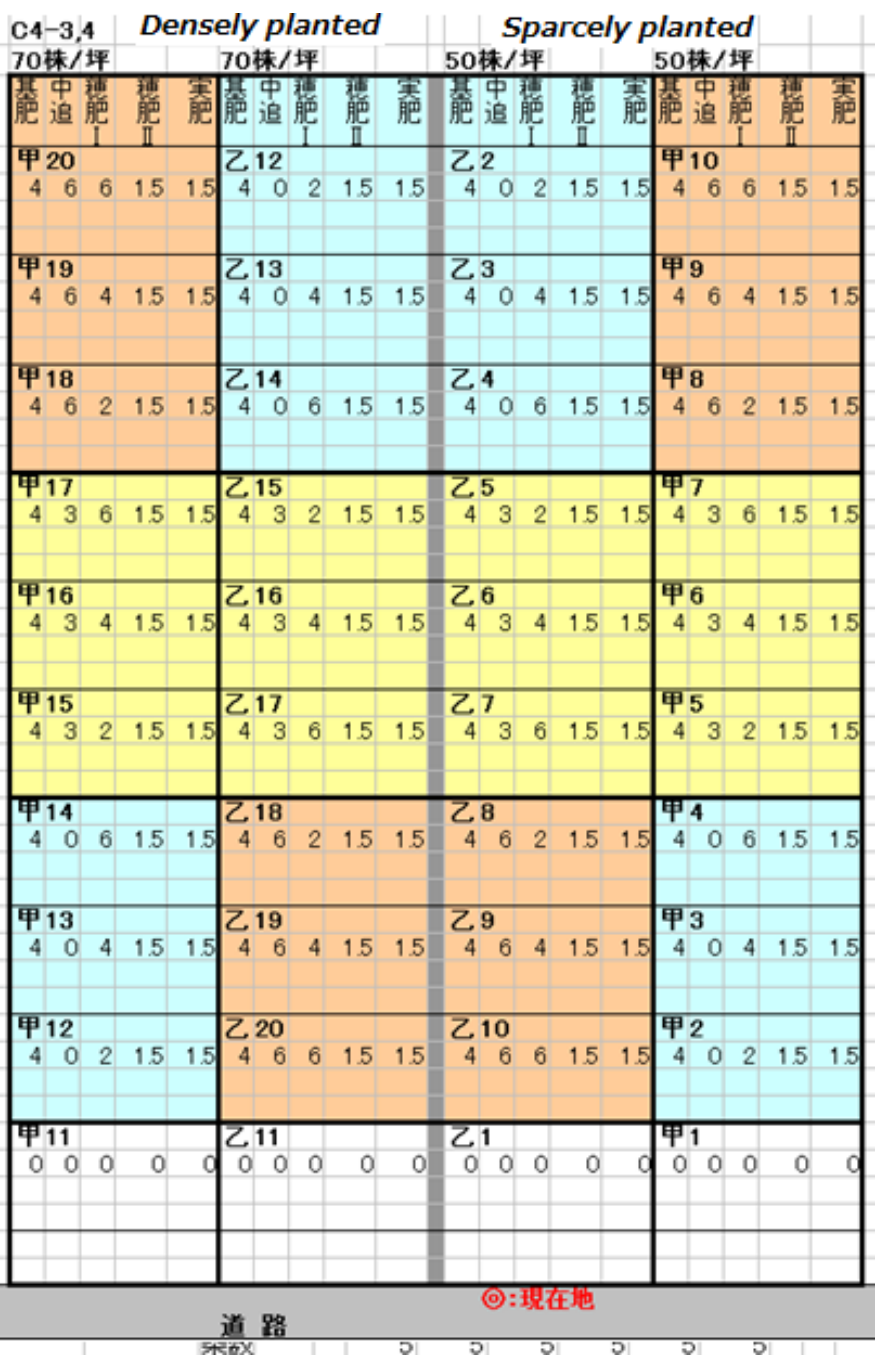

Fig. 3. Paddy filed layout for investigation of nitrogen of chemical fertilizer dependency on rice crop quality

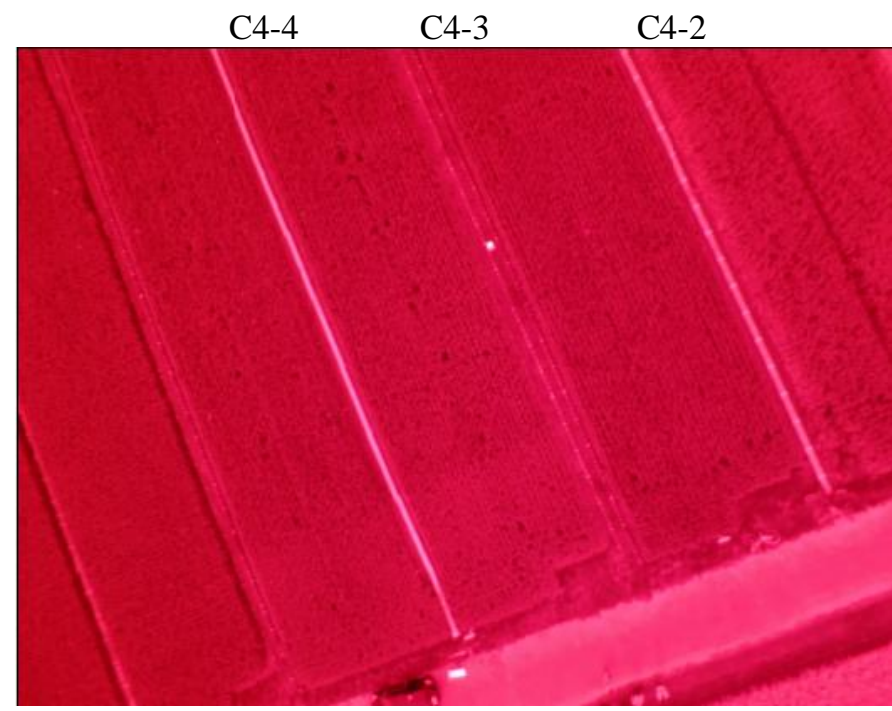

Fig. 4. Example of the acquired near infrared camera imagery data at SPARI on September 242012

\footnotetext{
${ }^{6} \mathrm{http} / / /$ note.chiebukuro.yahoo.co.jp/detail/n92075

${ }^{7} \mathrm{http}: / /$ www.scas.co.jp/service/apparatus/elemental_analyzer/sumigraph_nc220F.html
} 


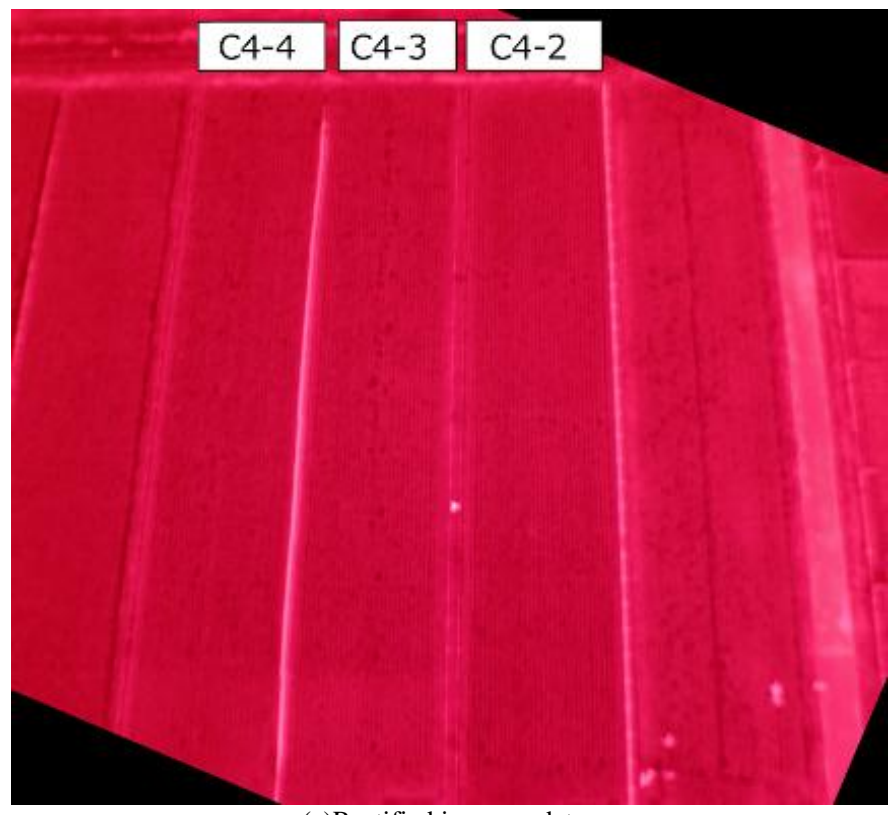

(a)Rectified imagery data

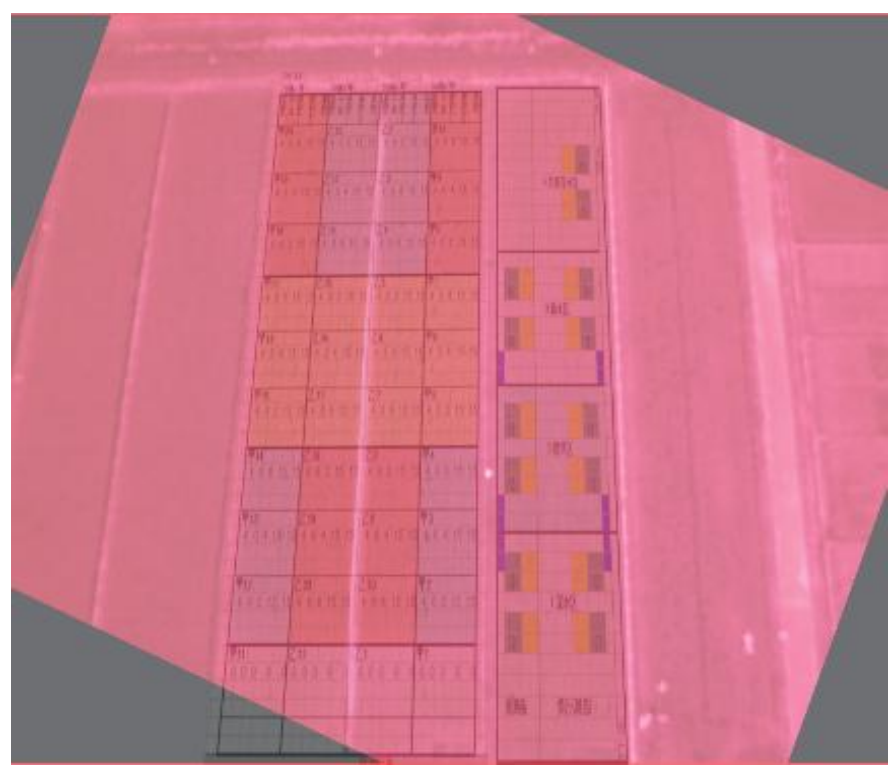

(b)Superimposed with geographical map of subsections of the paddy fields

Fig. 5. Rectified and geometrically matched near infrared camera imagery data to the geographical map

\section{B. Comparisons between EstimatedNnear Infrared Reflectance and Nitrogen Content Measured by Chemically}

Table 2 shows the calculated near infrared reflectance of the subsections with the different conditions of water supply conditions and nitrogen of chemical fertilizer and measured nitrogen content in the rice leaves.

Through regressive analysis with these dataset, the relation between near infrared reflectance and nitrogen content is estimated. The results show so good correlation with 0.026 of $\mathrm{R}^{2}$ value as shown in Figure 6.
TABLE II. ACTIVITY FOR 5 HIGHSET CATEGORY RESOLVED

\begin{tabular}{|l|c|c|}
\hline Plot & NIR Reflectance & Nitorogen Content( $)$ \\
\hline C4-2 1 & 0.7609 & 2.5913 \\
\hline C4-2 7 & 0.7939 & 2.5730 \\
\hline C4-2 11 & 0.7909 & 2.4011 \\
\hline C4-2 13 & 0.8093 & 2.4224 \\
\hline C4-3甲1 & 0.7868 & 1.9056 \\
\hline C4-3甲2 & 0.7781 & 2.2527 \\
\hline C4-3甲3 & 0.7755 & 2.6008 \\
\hline C4-3甲4 & 0.8038 & 2.5833 \\
\hline C4-3甲5 & 0.7982 & 2.4630 \\
\hline C4-3甲6 & 0.8184 & 2.6115 \\
\hline C4-3甲7 & 0.8086 & 3.0306 \\
\hline C4-3甲8 & 0.7992 & 2.9693 \\
\hline C4-3甲9 & 0.7768 & 2.8576 \\
\hline C4-3甲10 & 0.7581 & 2.7578 \\
\hline C4-4甲1 & 0.7757 & 1.9511 \\
\hline
\end{tabular}

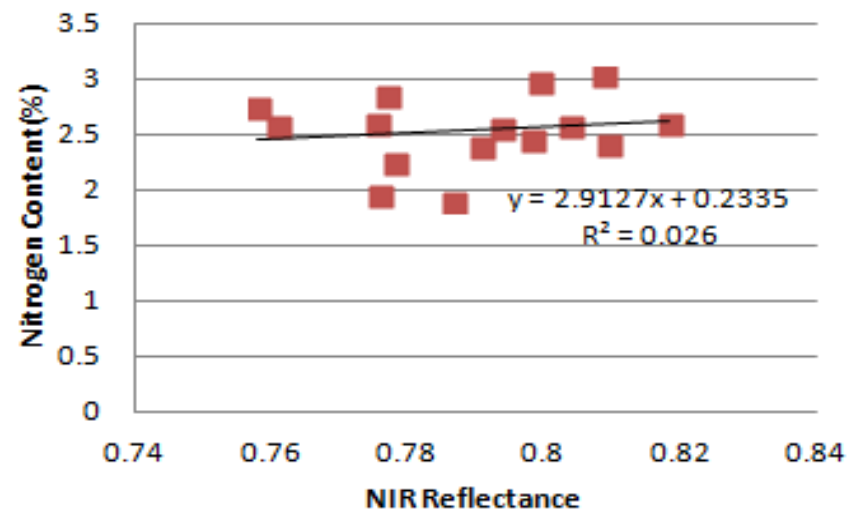

Fig. 6. Relation between Near Infrared: NIR reflectance and nitrogen content in the rice leaves

There are some influences due to shadow in the acquired near infrared images. When the pixels which do not affected by shadow are removed, then much nice relation between NIR reflectance and nitrogen content is obtained as shown in Figure 7. The results show much better correlation with 0.4971 of $\mathrm{R}^{2}$ value.

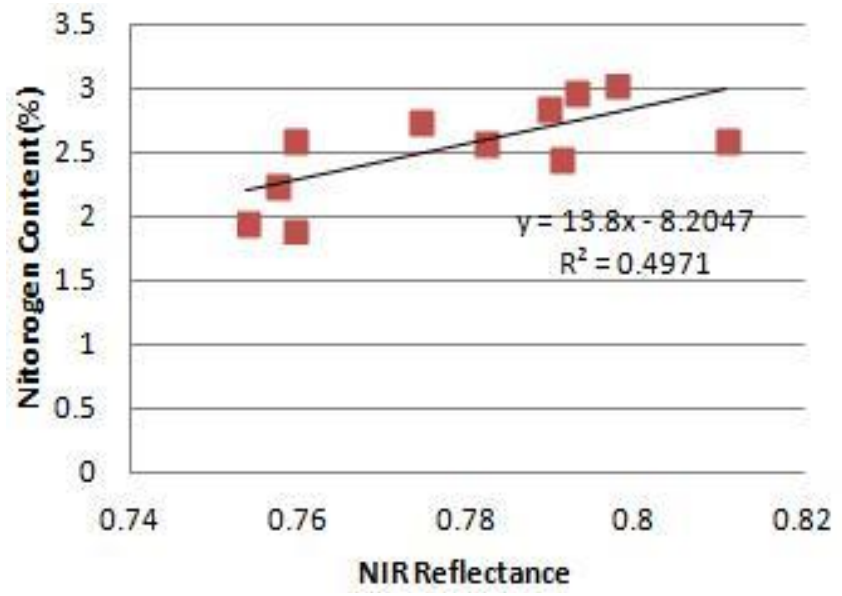

Fig. 7. Relation between Near Infrared: NIR reflectance and nitrogen content in the rice leaves after the pixel which affected by shadow is removed 
Figure 8 shows example of the histogram of the NIR camera data of the subsection of rice paddy fields (Typically, histogram is bi-modal characteristics so that it is easy to distinguish between the pixels which are suffered from the shadow influence. In this paper, Ohtsu's method is applied to the data for discrimination of the pixels.

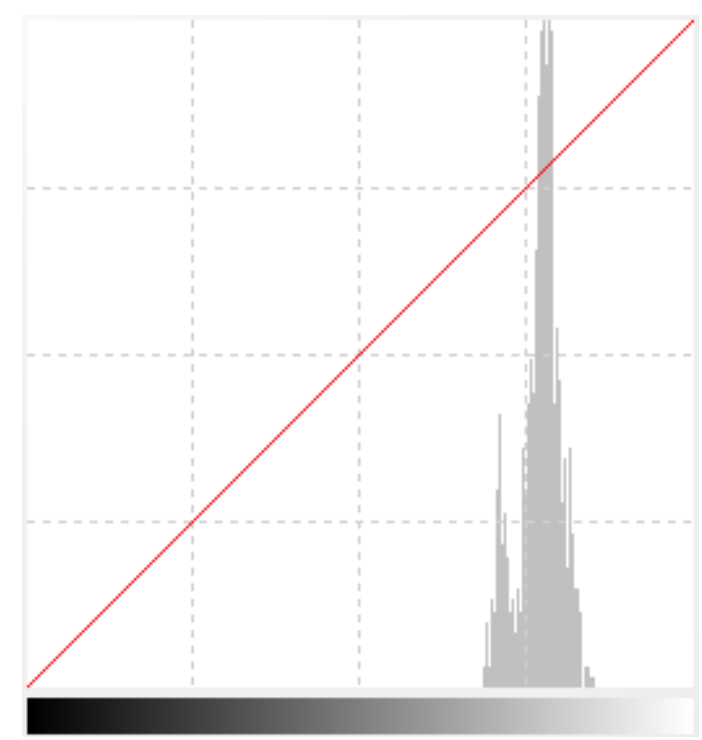

Fig. 8. Example of the histogram of the NIR camera data of the subsection of rice paddy fields (Typically, histogram is bi-modal characteristics so that it is easy to distinguish between the pixels which are suffered from the shadow influence.

Because we know the locations at where the sample of rice leaves are removed from the subsection of paddy fields, we could extract the pixels near the locations as shown in Figure 8. Dark portions in the paddy fields show the locations t where the sample of rice leaves are removed from the subsection of paddy fields. The pixels near the location are extracted for the investigation of relations between NIR reflectance and nitrogen content.

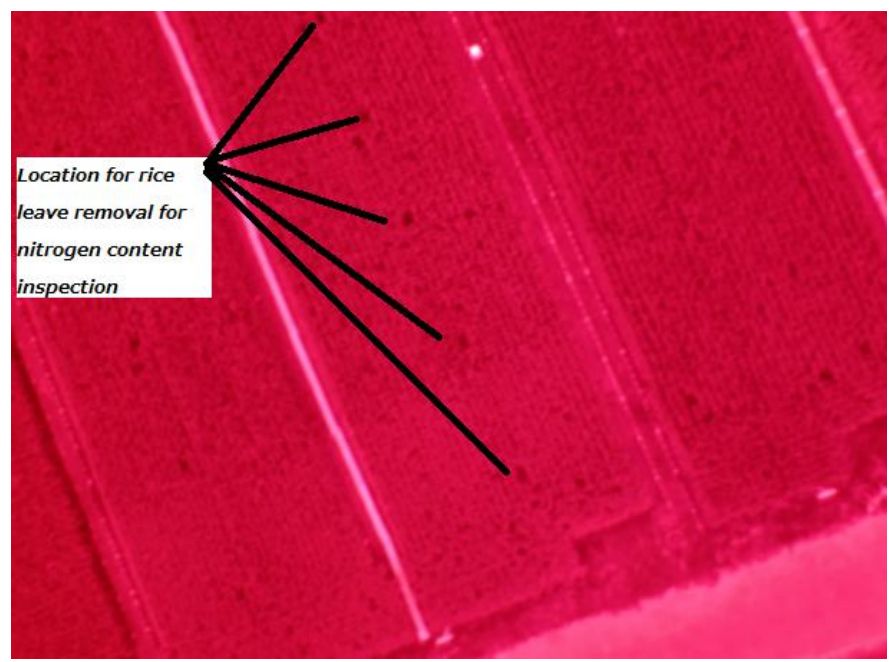

Fig. 9. Locations at where the sample of rice leaves are removed from the subsection of paddy fields
Then the relation between NIR reflectance and nitrogen content gets better up to 0.9674 of $R^{2}$ value as shown in Figure 9. The pair of NIR reflectance and nitrogen content is listed in Table 3.

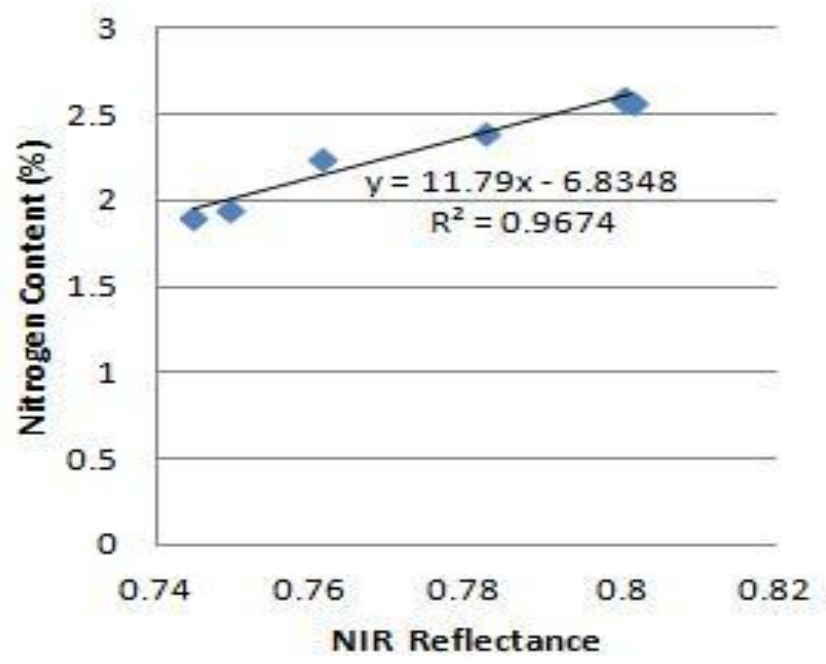

Fig. 10. Relation between nitrogen content in the rice leaves and near Infrared NIR reflectance of the rice leaves near the location at which the rice leaves are removed for nitrogen content measurements

TABLE III. ACTIVITY FOR 5 HIGHSET CATEGORY RESOLVED

\begin{tabular}{|l|c|c|}
\hline Plot & NIR Reflectance & Nitrogen Content $(\%)$ \\
\hline C4-3甲1 & 0.7448 & 1.9056 \\
\hline C4-3甲2 & 0.7613 & 2.2527 \\
\hline C4-3甲3 & 0.8003 & 2.6008 \\
\hline C4-3甲4 & 0.8015 & 2.5833 \\
\hline C4-4甲11 & 0.7492 & 1.9511 \\
\hline C4-21 & 0.8001 & 2.5912 \\
\hline C4-211 & 0.7823 & 2.4011 \\
\hline
\end{tabular}

\section{Uniformity Evaluation with Radio Conrtrolled Helicopter} Based NIR Camera:

During the period from August 15 to September 24 2012, the rice crop fields are observed with radio controlled helicopter mounted NIR camera. Examples of the acquired images on September 28 are shown in Figure 9. C4-2 is situated on the right side of the photos while C4-3 is seen on the left hand side. In the middle of the photos, there is spectralon. It looks a small dots due to the fact that helicopter altitude is $30 \mathrm{~m}$ so that Instantaneous Field of View: IFOV is around $1.1 \mathrm{~cm}$ (Pixel size). Figure 9 (a) shows entire one shot of the acquired image with FOV of PowerShot of NIR camera while Figure 9 (b) shows enlarged portion of the acquired image. Meanwhile, Figure 9 (c) and (d) shows another shot of image at the different time on the same day. These show a good repeatability and reproduceability. NIR reflecttance can be calculated by taking the ratio of the pixels value of the fields and that of Spectralon.

Uniformity in the small fields, C4-2, C4-3 are relatively good. Meanwhile, mean and variance are different by the samll fields due to the fact that the given chemical firtilizers are different each other small fields. 


\section{CONCLUSION}

Rice crop quality evaluation method through regressive analysis between nitrogen content in the rice leaves and near infrared reflectance measurement data from near field, from radio wave controlled helicopter is proposed. Rice quality dependency on nitrogen of chemical fertilizer and water supply condition is evaluated.

Also homogeneity of the rice crop quality in the paddy fields is evaluated. Furthermore, influence due to shadow on near infrared reflectance of rice leaves measured from near field is taken into account in the rice crop quality evaluation processes.

Through experiments at test paddy fields in Saga Prefectural Agricultural Research Institute.

\section{ACKNOWLEDGMENT}

The author would like to thank Dr. Osamu Shigetomi, Yuko Miura of the Saga Prefectural Agricultural Research Institute: SPARI and Mr. Hideaki Munemoto of Saga University for their great effort to conduct the experiments.

\section{REFERENCES}

[1] J.T.Compton, Red and photographic infrared linear combinations for monitoring vegetation, Journal of Remote Sensing of Environment, 8, 127-150, 1979.

[2] C.Wiegand, M.Shibayama, and Y.Yamagata, Spectral observation for estimating the growth and yield of rice, Journal of Crop Science, 58, 4, 673-683, 1989.

[3] Kohei Arai, Method for estimation of grow index of tealeaves based on Bi-Directional reflectance function:BRDF measurements with ground based netwrok cameras, International Journal of Applied Science, 2, 2, 52-62, 2011.

[4] Kohei Arai, Wireless sensor network for tea estate monitoring in complementally usage with Earth observation satellite imagery data based on Geographic Information System(GIS), International Journal of Ubiquitous Computing, 1, 2, 12-21, 2011.

[5] Kohei Arai, Method for estimation of total nitrogen and fiber contents in tealeaves with grond based network cameras, International Journal of Applied Science, 2, 2, 21-30, 2011.

[6] Kohei Arai, Method for estimation of damage grade and damaged paddy field areas sue to salt containing sea breeze with typhoon using remote sensing imagery data, International Journal of Applied Science,2,3,8492, 2011.

[7] Kohei Arai, Monte Carlo ray tracing simulation for bi-directional reflectance distribution function and grow index of tealeaves estimation, International Journal of Research and Reviews on Computer Science, 2, 6, 1313-1318, 2011.

[8] K.Arai, Fractal model based tea tree and tealeaves model for estimation of well opened tealeaf ratio which is useful to determine tealeaf harvesting timing, International Journal of Research and Review on Computer Science, 3, 3, 1628-1632, 2012.

[9] K.Arai, H.Miyazaki, M.Akaishi, Determination of harvesting timing of tealeaves with visible and near infrared cameradata and its application to tea tree vitality assessment, Journal of Japanese Society of Photogrammetry and Remote Sensing, 51, 1, 38-45, 2012

\section{AUTHORS PROFILE}

Kohei Aarai He received BS, MS and PhD degrees in 1972, 1974 and 1982 respectively. He was with The Institute for Industrial Science and Technology of the University of Tokyo from April 1974 to December 1978 and also was with National Space Development Agency of Japan from January, 1979 to March, 1990. During from 1985 to 1987, he was with Canada Centre for Remote Sensing as a Post Doctoral Fellow of National Science and Engineering Research Council of Canada. He moved to Saga University as a Professor in Department of Information Science on April 1990. He was a councilor for the Aeronautics and Space related to the Technology Committee of the Ministry of Science and Technology during from 1998 to 2000. He was a councilor of Saga University for 2002 and 2003. He also was an executive councilor for the Remote Sensing Society of Japan for 2003 to 2005 . He is an Adjunct Professor of University of Arizona, USA since 1998. He also is Vice Chairman of the Commission-A of ICSU/COSPAR since 2008. He wrote 30 books and published 332 journal papers. 